\title{
A case of small intestinal endometrioid adenocarcinoma
}

\author{
Yusuke Ogi ${ }^{1}$, Tomohiro Yamaguchi ${ }^{*}$, Yusuke Kinugasa', Akio Shiomi ${ }^{1}$, Hiroyasu Kagawa' ${ }^{1}$, Yushi Yamakawa ${ }^{1}$, \\ Masakatsu Numata', Akinobu Furutani ${ }^{1}$ and Masakazu Abe $^{2}$
}

\begin{abstract}
Endometriosis generally occurs in the ovary. Intestinal endometriosis is rare. About $1 \%$ of all endometriosis cases become malignant. Malignant transformation of small intestinal endometriosis is very rare. A 55-year-old woman who underwent total abdominal hysterectomy and bilateral salpingo-oophorectomy and omentectomy for endometriosis 7 years ago presented to her primary care doctor with melena. A tumor was detected in the right lower abdomen by ultrasonography. The doctor referred her to our hospital. Computed tomography demonstrated a lobulated tumor ventral to the right common iliac vessels. Magnetic resonance imaging demonstrated that the tumor had heterogeneous intensity on T2-weighted images. Several small cysts with high intensity were observed caudal to the tumor on T2-weighted images. We performed partial small intestinal resection for the lesion. The tumor was diagnosed as endometrioid adenocarcinoma of the small intestine. She has been relapse-free for 5 years after surgery. Only three cases of malignant transformation of small intestinal endometriosis have been reported previously. It is very rare for long-term survival to be obtained with surgery alone, as in our case. This case report highlights the imaging findings for malignant transformation of intestinal endometriosis.
\end{abstract}

Keywords: Endometriosis, Malignant transformation, Small intestine, Magnetic resonance imaging

\section{Background}

Endometriosis generally occurs in the ovary. It rarely involves the intestinal tract. Almost all reported cases of intestinal endometriosis involve the sigmoid colon and rectum [1]. There have been relatively few reports of endometriosis in the small intestine. Malignant transformation occurs in approximately $1 \%$ of all endometriosis cases [2]. We report a very rare case of endometrioid adenocarcinoma, which is endometriosis with malignant transformation, in the small intestine.

\section{Case presentation}

A 55-year-old woman presented to her primary care doctor with melena. A tumor in the right lower abdomen was detected by ultrasonography. The doctor referred her to our hospital for further examination and treatment. She underwent total abdominal hysterectomy

\footnotetext{
* Correspondence: t.yamaguchi@scchr.jp

${ }^{1}$ Division of Colon and Rectal Surgery, Shizuoka Cancer Center Hospital, 1007 Shimonagakubo, Nagaizumi-cho, Sunto-gun, Shizuoka 411-8777, Japan Full list of author information is available at the end of the article
}

and bilateral salpingo-oophorectomy and omentectomy for endometriosis 7 years ago.

On physical examination, a tumor was slightly palpable in the right lower abdomen. Computed tomography of the abdomen demonstrated a $6.5 \times 4 \mathrm{~cm}$ lobulated tumor ventral to the right common iliac vessels. Enlarged lymph nodes were observed in the area of the ileocolic artery. She also underwent a contrast-enhanced magnetic resonance (MR) imaging examination. The tumor had intermediate signal intensity, similar to that of muscle, on T1-weighted images and heterogeneous intensity on T2-weighted images. On contrast-enhanced MR images with gadolinium, the mass was enhanced heterogeneously. Several small cysts that were hypointense on T1-weighted images and hyperintense on T2-weighted images were observed caudal to the tumor (Fig. 1).

Blood tests revealed anemia, with a hemoglobin concentration of $8.5 \mathrm{~g} / \mathrm{dL}$. Serum concentrations of carcinoembryonic antigen and carbohydrate antigen 125 were $1.7 \mathrm{ng} / \mathrm{mL}$ and $14 \mathrm{U} / \mathrm{mL}$, respectively. Endoscopic examination did not detect any tumors or sites of bleeding in the colon. 


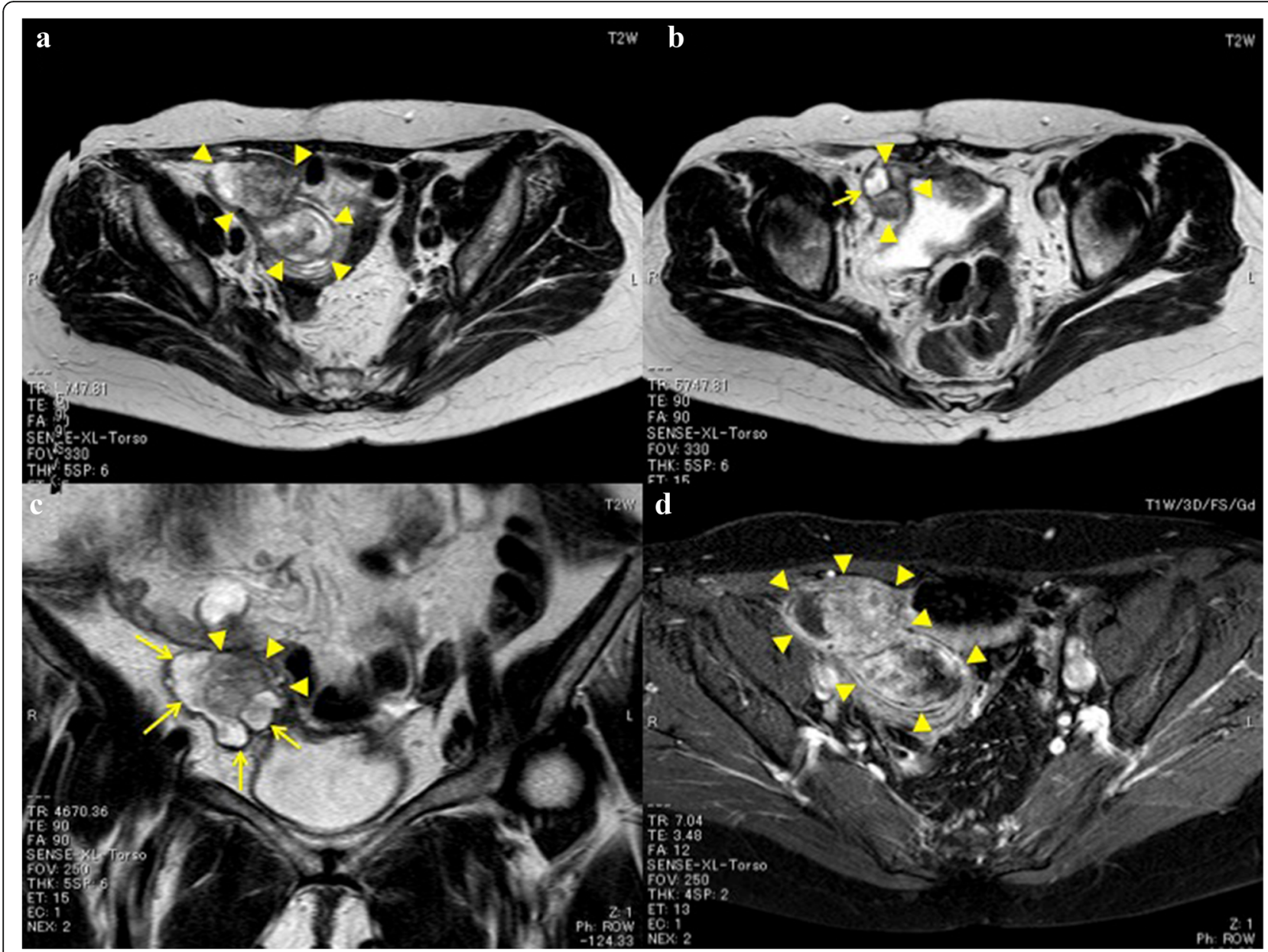

Fig. 1 MR imaging. a T2-weighted imaging. A lobulated tumor was observed ventral to the right common iliac artery. The tumor had heterogeneous intensity. b, c T2-weighted imaging. Some high-intensity cystic lesions (arrow) were detected around the tumor. $\mathbf{d}$ T1-weighted imaging. The mass had heterogeneous enhancement (arrowheads indicate the outline of the tumor)

We suspected primary small intestinal cancer, a retroperitoneal tumor with invasion to the small bowel, or endometriosis with malignant transformation. Surgery was performed. Intraoperatively, we observed that the tumor was located ventral to the right common iliac vessels. Because the tumor invaded the ileum $35 \mathrm{~cm}$ proximal to the end of the ileum, we performed partial small intestinal resection (Fig. 2).

Histologically, the tumor penetrated to the mucosa of the small intestine. The tumor consisted of two types of stromal tissue (endometriosis type and ovarian type) and atypical endometrioid glandular epithelium. The atypical cells were immunopositive for cytokeratin 7 but were negative for cytokeratin 20. The histopathological diagnosis was endometrioid adenocarcinoma (Fig. 3). The stromal tissues in the wall of the small intestine surrounded the adenocarcinoma component. The endometrioid adenocarcinoma was localized in the intestinal wall. Small intestinal endometriosis was considered the site of malignant transformation. There was no lymph node metastasis. Postoperative chemotherapy was not performed. She has been relapse-free for 5 years after surgery.

\section{Discussion}

The clinical course of this patient illustrates two important clinical points. Malignant transformation of endometriosis can occur in the small intestine. MR imaging is useful in the diagnostic evaluation of malignant endometriosis in the small intestine.

First, malignant transformation of endometriosis can occur in the small intestine. The ovary is the site of $80 \%$ of all endometriosis cases. Abdominal endometriosis accounts for 5.3 to $12 \%$ of endometriosis [3]. Intestinal endometriosis mainly occurs in the sigmoid colon and rectum, and these two sites account for $77 \%$ of abdominal endometriosis [1]. About $1 \%$ of all endometriosis cases become malignant [2]. Only three cases of malignant endometriosis in the small intestine have been reported (Table 1) [4-6]. It is very 


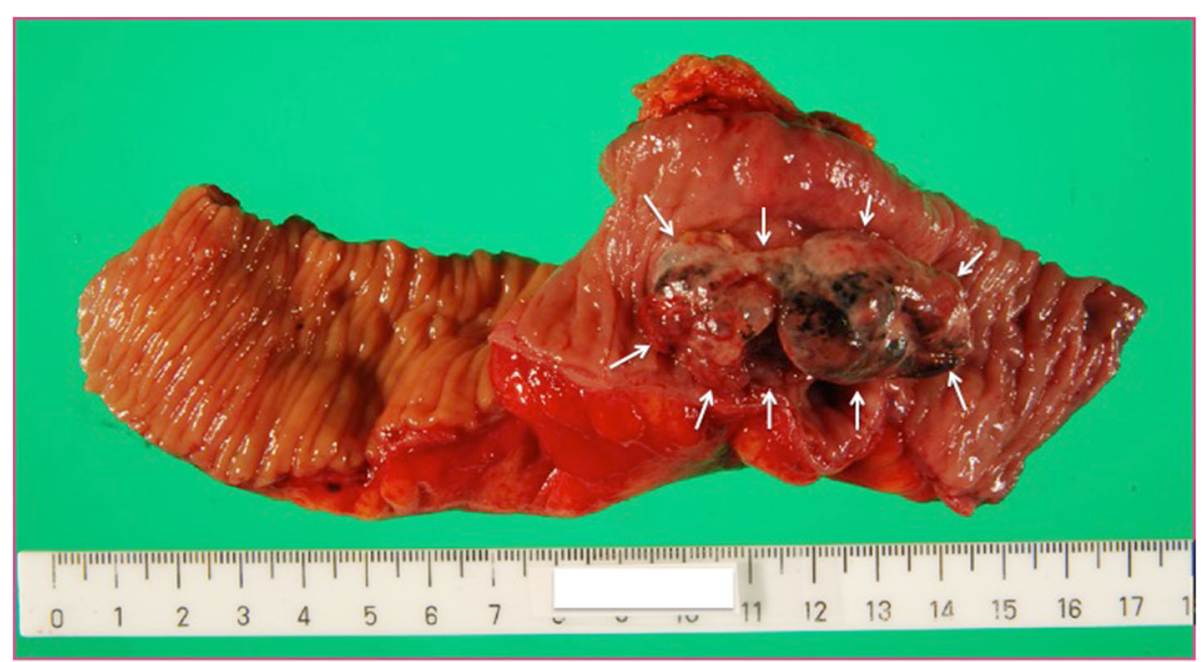

Fig. 2 Macroscopic findings. The tumor (arrows) invaded the intestinal mucosa

rare for long-term survival to be obtained with surgery alone, as in our case.

Second, MR imaging is useful for diagnosing malignant endometriosis in the small intestine. Endometriosis in the rectum is often assessed with MR imaging, with very high diagnostic accuracy. Compared to rectal endometriosis, the diagnostic accuracy of intestinal endometriosis with MR imaging is lower [7]. Endometriosis in the acute phase is characterized by high signal intensity on both T1- and T2-weighted images, which is suggestive of the presence of subacute hemorrhage. During the chronic phase, shading, which is defined as a centrally or peripherally located low-intensity area in a hyperintense cyst, can be observed on T2-weighted images [8]. If solid nodules exist in a cyst, there is a possibility of malignant transformation. Contrast-enhanced MR imaging with gadolinium is considered when solid components of endometriosis are suspected to be malignant. In the study of mural nodules within cysts, malignant endometriosis is characterized by the lack of shading on T2weighted images, high signal intensity on diffusionweighted images, and heterogeneous enhancement on MR images with contrast [9]. In our case, the tumor had surrounding small cysts with low intensity on T1weighted images, heterogeneous intensity on T2weighted images, and heterogeneous enhancement on T1-weighted images with contrast. Small cysts are considered to reflect endometriosis, while heterogeneous

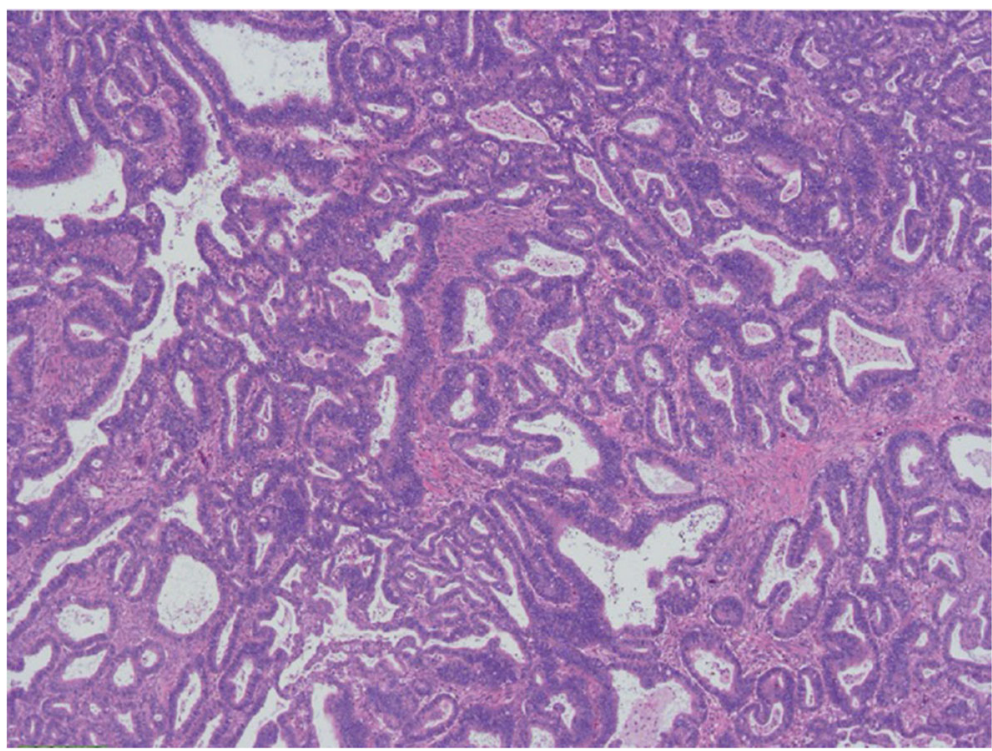

Fig. 3 Microscopic findings. Sixteen tumor cells had nuclear atypia and irregular glandular structures (hematoxylin-eosin 17 stain, $\times 40$ ) 
Table 1 Reports of endometriosis with malignant transformation in the small intestine

\begin{tabular}{|c|c|c|c|c|c|c|c|c|}
\hline Case & Author & Year & Age & Past surgical history & Histology & Postoperative therapy & Survival & Reference \\
\hline \multirow[t]{5}{*}{1} & Ferraro et al. & 1956 & 44 & $\begin{array}{l}\text { 1. Left partial oophorectomy } \\
\text { for endometriosis }\end{array}$ & Endometriotic sarcoma & Radiation therapy & $\begin{array}{l}\text { Died of disease } \\
4 \text { months after } \\
\text { surgery }\end{array}$ & {$[4]$} \\
\hline & & & & $\begin{array}{l}\text { 2. Right oophorectomy for } \\
\text { corpus luteum cyst }\end{array}$ & & & & \\
\hline & & & & $\begin{array}{l}\text { 3. Supravaginal hysterectomy } \\
\text { for fibromyoma }\end{array}$ & & & & \\
\hline & & & & $\begin{array}{l}\text { 4. Removal of a right } \\
\text { intraligamentous chocolate } \\
\text { cyst with endometriosis }\end{array}$ & & & & \\
\hline & & & & $\begin{array}{l}\text { 5. Colon resection for pelvic } \\
\text { endometrioma }\end{array}$ & & & & \\
\hline 2 & Baiocchii et al. & 1990 & 38 & TAH and BSO for endometriosis & $\begin{array}{l}\text { Endometrioid stromal } \\
\text { sarcoma }\end{array}$ & Chemotherapy & No contributions & [5] \\
\hline 3 & Makihara et al. & 2015 & 25 & None & $\begin{array}{l}\text { Endometrioid } \\
\text { adenocarcinoma }\end{array}$ & None & $\begin{array}{l}\text { Disease-free for } \\
10 \text { months }\end{array}$ & [6] \\
\hline 4 & Present case & 2016 & 55 & $\begin{array}{l}\text { TAH and BSO and omentectomy } \\
\text { for endometriosis }\end{array}$ & $\begin{array}{l}\text { Endometrioid } \\
\text { adenocarcinoma }\end{array}$ & None & $\begin{array}{l}\text { Disease-free for } \\
5 \text { years }\end{array}$ & - \\
\hline
\end{tabular}

TAH total abdominal hysterectomy, BSO bilateral salpingo-oophorectomy

enhancement on T1-weighted images reflects malignant transformation. In patients with a history of endometriosis, when a tumor with cysts is detected, we need to consider the possibility of malignant transformation arising from intestinal endometriosis. Contrast-enhanced MR imaging may be useful in the diagnostic evaluation of malignant endometriosis in the small intestine.

Surgical resection is the first-choice treatment for malignant endometriosis. Lymph node metastasis and peritoneal dissemination have been reported to be poor prognostic factors $[10,11]$. Patients with either factor may benefit from postoperative chemotherapy. In the case of endometrioid adenocarcinoma of the ovary, the recommended postoperative chemotherapy regimen is carboplatin plus paclitaxel $[12,13]$. If the tumor is localized and well differentiated and there is no lymph node metastasis, postoperative chemotherapy may be omitted in ovarian cancer. However, the evidence base for postoperative chemotherapy to treat intestinal malignant endometriosis has not been fully established because of the small number of cases. In the present case, endometrioid adenocarcinoma was localized to the intestinal wall, resection margins were negative, and complete resection was performed. There was no lymph node metastasis and histological examination showed that the tumor was well differentiated. We consulted with the patient and decided not to perform postoperative chemotherapy.

\section{Conclusions}

Malignant endometriosis can arise in the small intestine and MR imaging is useful for diagnosing endometriosis with malignant transformation. Although there is a need to accumulate more cases, we propose that contrast-enhanced MR imaging is useful for detecting malignant transformation of intestinal endometriosis.

\section{Abbreviations \\ BSO: Bilateral salpingo-oophorectomy; MR: Magnetic resonance; TAH: Total abdominal hysterectomy}

\section{Acknowledgements}

None.

\section{Authors' contributions}

YO and TY drafted the manuscript. YK, AS, HK, YY, MN, AF, and MA collected the clinical, radiological, and pathological data and helped draft the manuscript. YK reviewed the manuscript. All authors read and approved the final manuscript.

\section{Competing interests}

The authors declare that they have no competing interests.

\section{Consent for publication}

Written informed consent was obtained from the patient for publication

of this case report and accompanying images. A copy of the consent

document is available for review by the editor-in-chief of this journal.

\section{Author details}

${ }^{1}$ Division of Colon and Rectal Surgery, Shizuoka Cancer Center Hospital, 1007 Shimonagakubo, Nagaizumi-cho, Sunto-gun, Shizuoka 411-8777, Japan.

2Division of Gynecology, Shizuoka Cancer Center Hospital, 1007

Shimonagakubo, Nagaizumi-cho, Sunto-gun, Shizuoka 411-8777, Japan.

Received: 17 May 2016 Accepted: 8 September 2016

Published online: 14 September 2016

\section{References}

1. Masson JC. Present conception of endometriosis and its treatment. Collected papers of the Mayo Clinic and the Mayo Foundation Mayo Clinic. 1946;37:205-9.

2. Van Gorp T, Amant F, Neven P, Vergote I, Moerman P. Endometriosis and the development of malignant tumours of the pelvis. A review of literature. 
Best Pract Res Clin Obstet Gynaecol. 2004;18(2):349-71. doi:10.1016/j. bpobgyn.2003.03.001.

3. Bassi MA, Podgaec S, Dias Junior JA, Sobrado CW, D Amico Filho N. Bowel endometriosis: a benign disease? Revista da Associacao Medica Brasileira (1992). 2009;55(5):611-6.

4. Ferraro LR, Hetz H, Carter H. Malignant endometriosis; pelvic endometriosis complicated by polypoid endometrioma of the colon and endometriotic sarcoma; report of a case and review of the literature. Obstet Gynecol. 1956; 7(1):32-9.

5. Baiocchi G, Kavanagh JJ, Wharton JT. Endometrioid stromal sarcomas arising from ovarian and extraovarian endometriosis: report of two cases and review of the literature. Gynecol Oncol. 1990;36(1):147-51.

6. Makihara N, Fujita I, Soudaf H, Yamamoto T, Sashikata T, Mukohara T, et al. A case of endometrioid adenocarcinoma originating from the serous surface of the small intestine. Rare tumors. 2015:7(3):5932. doi:10.4081/rt. 2015.5932.

7. Medeiros LR, Rosa MI, Silva BR, Reis ME, Simon CS, Dondossola ER, et al. Accuracy of magnetic resonance in deeply infiltrating endometriosis: a systematic review and meta-analysis. Arch Gynecol Obstet. 2015;291(3): 611-21. doi:10.1007/s00404-014-3470-7.

8. Nishimura K, Togashi K, Itoh K, Fujisawa I, Noma S, Kawamura Y, et al. Endometrial cysts of the ovary: MR imaging. Radiology. 1987;162(2):315-8. doi:10.1148/radiology.162.2.3797643.

9. Tanaka YO, Yoshizako T, Nishida M, Yamaguchi M, Sugimura K, Itai Y Ovarian carcinoma in patients with endometriosis: MR imaging findings. AJR Am J Roentgenol. 2000;175(5):1423-30. doi:10.2214/ajr.175.5.1751423.

10. Heaps JM, Nieberg RK, Berek JS. Malignant neoplasms arising in endometriosis. Obstet Gynecol. 1990;75(6):1023-8.

11. Yantiss RK, Clement PB, Young RH. Neoplastic and pre-neoplastic changes in gastrointestinal endometriosis: a study of 17 cases. Am J Surg Pathol. 2000;24(4):513-24.

12. Ozols RF, Bundy BN, Greer BE, Fowler JM, Clarke-Pearson D, Burger RA, et al. Phase III trial of carboplatin and paclitaxel compared with cisplatin and paclitaxel in patients with optimally resected stage III ovarian cancer: a Gynecologic Oncology Group study. J Clin Oncol. 2003;21(17):3194-200. doi:10.1200/jco.2003.02.153.

13. du Bois A, Luck HJ, Meier W, Adams HP, Mobus V, Costa S, et al. A randomized clinical trial of cisplatin/paclitaxel versus carboplatin/ paclitaxel as first-line treatment of ovarian cancer. J Natl Cancer Inst. 2003;95(17):1320-9.

\section{Submit your manuscript to a SpringerOpen ${ }^{\circ}$ journal and benefit from:}

- Convenient online submission

- Rigorous peer review

- Immediate publication on acceptance

- Open access: articles freely available online

- High visibility within the field

- Retaining the copyright to your article 